\title{
Qualidade ambiental dos fragmentos florestais na Bacia Hidrográfica do Rio Jundiaí-Mirim entre 1972 e 2013
}

\author{
Felipe H. Fengler ${ }^{1}$, Jener F. L. de Moraes ${ }^{2}$, Admilson I. Ribeiro ${ }^{3}$, \\ Afonso Peche Filho ${ }^{4}$, Moisés Storino ${ }^{5}$ \& Gerson A. de Medeiros ${ }^{6}$
}

\section{Palavras-chave:}

análise multicritério perturbação ambiental uso e ocupação do solo sensoriamento remoto

\begin{abstract}
R E S U M O
A localização da Bacia Hidrográfica do Rio Jundiaí-Mirim, próximo a grandes centros urbanos e parques industriais, tem contribuído para a valorização das suas terras; em consequência, a região apresenta intenso processo de urbanização, que resultou em um aumento crescente da perturbação ambiental nas áreas florestais. Dada à necessidade de manutenção da vegetação natural, visto que a bacia hidrográfica é a fonte da água utilizada no abastecimento de Jundiaí, SP, este trabalho avaliou as modificações na qualidade ambiental dos fragmentos florestais da bacia hidrográfica entre 1972 e 2013 . A qualidade ambiental foi determinada por meio da avaliação de nove indicadores de perturbação ambiental obtidos através de técnicas de Geoprocessamento e integrados pela Análise Multicritério. Os resultados mostraram uma tendência constante de deterioração da qualidade ambiental da vegetação natural entre 1972 e 2013, atribuída ao intenso processo de ocupação da bacia hidrográfica. Concluiu-se que: (a) a urbanização e o desmatamento da vegetação natural foram os principais responsáveis pelas alterações na qualidade ambiental; (b) existe a necessidade de criação de políticas públicas para a preservação da vegetação natural do manancial.
\end{abstract}

\section{Key words:}

multicriteria analysis environmental disturbance land use and occupation remote sensing

\section{Environmental quality of forest fragments in Jundiaí-Mirim river basin between 1972 and 2013}

\begin{abstract}
A B S T R A C T
The location of Jundiaí-Mirim river basin, close to large urban centers and industrial parks, has contributed to the appreciation of their lands. Consequently, the region has an intense process of urbanization that resulted in an increasing environmental disturbance in the forest areas. Given the need to preserve existing natural vegetation, because the watershed is the source of water used to supply Jundiaí, SP, this study evaluated changes in the environmental quality of the watershed forest fragments between 1972 and 2013. The environment quality was determined by evaluating nine indicators of environmental disturbance, obtained by techniques of Geoprocessing and integrated by Multicriteria Analysis. The results showed a constant tendency of deteriorating the environmental quality of natural vegetation between 1972 and 2013, attributed to the intense process of occupation of the watershed. It is concluded that: (a) urbanization and deforestation of natural vegetation were primarily responsible for changes in environmental quality; (b) there is a need to create public policies to preserve the natural vegetation in the watershed.
\end{abstract}

Protocolo 137-2014 - 27/04/2014 • Aprovado em 14/11/2014 • Publicado em 02/03/2015

${ }^{1}$ IAC. Campinas, SP. E-mail: felipe_fengler@hotmail.com (Autor correspondente)

${ }^{2}$ Centro de Solos e Recursos Ambientais/IAC. Campinas, SP. E-mail: jfmoraes@iac.sp.gov.br

${ }^{3}$ UNESP. Sorocaba, SP. E-mail: admilson@sorocaba.unesp.br

${ }^{4}$ Centro de Engenharia e Automação/IAC. Jundiaí, SP. E-mail: peche@iac.sp.gov.br

${ }^{5}$ Centro de Engenharia e Automação/IAC. Jundiaí, SP. E-mail: storino@iac.sp.gov.br

${ }^{6}$ UNESP. Sorocaba, SP. E-mail: gerson@sorocaba.unesp.br 


\section{INTRODUÇÃo}

A expansão da população humana requer a conversão dos sistemas naturais em outros usos, porém em função dos danos ambientais gerados e do comprometimento da capacidade de fornecimento de serviços ambientais, há uma sensibilização crescente sobre a importância do meio natural na manutenção da qualidade de vida da sociedade.

Mondal \& Southworth (2010) explicam que a composição do sistema ambiental natural é tão complexa que qualquer alteração em suas características pode afetar as interações dos elementos ecossistêmicos resultando em modificações não previstas nas etapas de planejamento e avaliação de impacto ambiental.

Neste sentido, vários podem ser os resultados do processo de ocupação dos habitats naturais, inclusive severos impactos ambientais negativos, como intensificação do processo erosivo, alterações na hidrologia de bacias hidrográficas, liberação de dióxido de carbono para atmosfera, declínio da biodiversidade, diminuição da disponibilidade de água e desertificação, entre outros (Haines-Young, 2009; Li et al., 2009; Poelmans et al., 2010; Ruhoff et al., 2010; Alkharabsheh et al., 2013; Ozturk et al., 2013).

A situação se agrava com a ocupação de regiões localizadas em mananciais. Chaves \& Santos (2009) explicam que as bacias hidrográficas mais impactadas no tocante à qualidade e disponibilidade da água, são aquelas que sofrem processo de ocupação acelerada e não planejada. Os autores afirmam que o valor de $10 \%$ de impermeabilização do solo promove degradação significativa dos ecossistemas hídricos, principalmente por modificações na hidrologia da bacia hidrográfica.

Outro produto que induz a diversas alterações de longo prazo nos ecossistemas naturais é a fragmentação florestal. Muitos processos ecológicos são afetados promovendo a redução da biodiversidade, a invasão biológica por espécies exógenas adaptadas à nova condição ambiental e à ocorrência do efeito de borda (Ramos et al., 2008; Newman et al., 2014).

Desta forma e embora as áreas remanescentes ao processo de ocupação sejam conservadas ao longo do tempo, em termos de dimensão, as perturbações causadas pelo uso e ocupação do solo das áreas de entorno podem alterar significativamente a composição e a estrutura florestal, resultando em mosaicos muito diferentes dos existentes na floresta original (Vieira et al., 2009).

Portanto, há uma premente necessidade de se entender a evolução do processo de ocupação nas regiões naturais, sobretudo a evolução da perturbação ambiental incidente nas áreas florestais de regiões que produzem serviços ambientais à sociedade (Bracchetti et al., 2012).

Neste contexto se insere a bacia hidrográfica do rio JundiaíMirim, a qual exerce grande influência na qualidade de vida da população do município de Jundiaí, no estado de São Paulo, pois constitui a fonte da água utilizada no abastecimento público e sofre com uma grande pressão pelo processo de urbanização.

Dada à necessidade de preservação das áreas remanescentes lá existentes, este trabalho avaliou por meio da análise de indicadores de perturbação ambiental e da análise multicritério, as alterações na qualidade ambiental dos fragmentos florestais na bacia do rio Jundiaí-Mirim entre 1972 e 2013.

\section{Material e Métodos}

A área de estudo se situa no estado de São Paulo, entre as latitudes $23^{\circ} 00^{\prime}$ e $23^{\circ} 30^{\prime}$ Sul e longitudes $46^{\circ} 30^{\prime}$ e $47^{\circ} 15^{\prime}$ Oeste; sua extensão é de 11.750 ha dos quais $55 \%$ se encontram no município de Jundiaí, 36,6\% no município de Jarinu e 8,4\% no município de Campo Limpo Paulista. Está localizada na zona hidrográfica do Médio Tietê Superior, na Unidade de Gerenciamento de Recursos Hídricos do Piracicaba, Capivari e Jundiaí, sendo subdividida em 18 sub-bacias hidrográficas tendo, como rio principal, o Jundiaí-Mirim.

A bacia hidrográfica é declarada, pela Lei municipal $\mathrm{N}^{\circ}$ 2.405/2010, como área de proteção, apresentando uso do solo disciplinado, com restrições para implantação de atividades que ameacem os recursos hídricos. Porém loteamentos, áreas densamente urbanizadas e de mineração ocupam grande extensão territorial na bacia hidrográfica.

O processo de desmatamento também se tem apresentado significativo com a supressão de $23 \%$ das áreas de mata ciliar entre 1972 e 2001 (Moraes et al., 2003; Prado, 2005).

Visando à realização do estudo foram utilizadas vinte e sete fotografias aéreas, referentes a 1972, em escala 1:25.000; um ortofoto digital, referente a 2001; mapa de capacidade de uso das terras e mapa de sub-bacias hidrográficas (Moraes et al., 2003; Prado, 2005; Freitas, 2012).

As fotografias aéreas foram digitalizadas por um escâner A4 e processadas no programa ILWIS Integrated Land and Water Information System (ITC, 2001). Realizou-se sua correção ortogonal iniciando com a mensuração das marcas fiduciais e determinação distância focal nos registros das fotografias; posteriormente as imagens foram georreferenciadas tomandose a imagem de 2001 como a referência espacial. O método de transformação linear Affine foi utilizado e o Erro Médio Quadrático (Root Mean Square - RMS) se manteve entre 0,5 e 3,5 $\sigma$, com valor médio de $1,4 \sigma$.

$\mathrm{Na}$ construção da imagem atual do local foram utilizadas quarenta e quatro imagens, obtidas pelo programa Google Earth', capturadas entre 29/06/2012 e 09/04/2013. O georreferenciamento foi realizado no programa ILWIS, tendo a imagem digital de 2001 como referência espacial. O RMS se manteve entre 0,2 e 1,7 $\sigma$ e valor médio obtido foi de $0,8 \sigma$.

Os mosaicos foram gerados com auxílio do programa Environment for Visualizing Images, Sulsoft (ENVI, 2009), através do processo de colagem baseado na referência espacial. Toda a base cartográfica adotou o Sistema de Projeção UTM (Universal Transversa de Mercator), Datum horizontal SAD69, Elipsoide South American 1969, Zona 23 Sul.

A qualidade ambiental dos fragmentos florestais foi determinada através da proposta metodológica desenvolvida por Freitas (2012) utilizando nove indicadores de perturbação ambiental integrados pelo método de análise multicritério Programação por Compromisso, no programa ILWIS (Eq. 1).

\footnotetext{
Qff $=(0,099 \times$ PROXED $)+(0,101 \times$ PROXVIAS $)+(0,062 \times$ SUPDESV $)+$

$+(0,132 \times$ BORDA $)+(0,124 \times \mathrm{IF})+(0,101 \times \mathrm{CV})+(0,142 \times \mathrm{TAMANHO})+(1)$

$+(0,116 \times \mathrm{INB})+(0,124 \times \mathrm{CONECT})$
} 
em que:

Qff - qualidade ambiental dos fragmentos florestais

PROXED - proximidade entre fragmentos florestais e áreas edificadas: assume que quanto maior a proximidade com as áreas edificadas, maior também a perturbação ambiental das áreas florestais considerando-se que em distâncias superiores a $200 \mathrm{~m}$ não existem efeitos sobre a vegetação natural.

PROXVIAS - proximidade entre fragmentos florestais e malha viária: estabelece que quanto maior a proximidade com a malha viária maior será a perturbação ambiental das áreas florestais assumindo que em distâncias superiores a 200 m não existem efeitos sobre a vegetação natural.

SUPDESV - suporte ao desenvolvimento da vegetação nativa: relaciona a capacidade de uso das terras com a resiliência da vegetação natural e sua capacidade de suportar pressões externas.

BORDA - uso e ocupação do solo na borda dos fragmentos florestais: assume que as alterações nas características ambientais naturais decorrentes do uso e da ocupação do solo no entorno dos fragmentos florestais, promovem modificações no ecossistema florestal, criando um ambiente perturbado.

IF - intensidade de fragmentação da vegetação nas subbacias hidrográficas: considera a relação entre o número de fragmentos florestais e a área total da sub-bacia hidrográfica.

CV - cobertura vegetal remanescente: estabelece a relação entre a área de cobertura vegetal natural e a área total da subbacia hidrográfica.

TAMANHO - tamanho dos fragmentos florestais: assume que a intensidade da perturbação ambiental é maior em fragmentos florestais de baixa dimensão e menor em fragmentos florestais de maior dimensão.

INB - índice de borda dos fragmentos florestais: relaciona a forma do fragmento florestal com o nível de perturbação ambiental através do índice de circularidade (Eq.2). Quanto mais compacto menor a vulnerabilidade dos fragmentos florestais às atividades de uso do solo do entorno visto que a porção central do fragmento tende a se manter equidistante da borda, relativamente protegida. Quanto mais alongado maior é vulnerabilidade. A porção central pode apresentar-se próxima à borda, resultando em uma interação maior entre os efeitos do uso e a ocupação do solo no entorno e a porção central do fragmento florestal.

$$
\mathrm{Ic}=\frac{(2 \times \sqrt{\pi \mathrm{A}})}{\mathrm{L}}
$$

em que:

Ic - índice de circularidade

A - área do fragmento florestal

L - perímetro do fragmento florestal

CONECT - conectividade dos fragmentos florestais: assume que fragmentos florestais isolados apresentam menor diversidade genética e de espécies, pela dificuldade de acesso da fauna e propagação de sementes sendo, portanto, mais perturbados.

Os indicadores quantificam, nas áreas florestais, os diferentes níveis de perturbação consequentes do uso e da ocupação da bacia hidrográfica. Para facilitar a interpretação da condição ambiental das áreas florestais realizou-se a normalização dos resultados em uma escala numérica de 0 a 1 através de uma função de conversão linear no programa ILWIS, conforme a Eq. 3.

$$
\mathrm{Y}=\left(\mathrm{X}-\mathrm{E}_{\min }\right) \times \frac{\left(\mathrm{S}_{\max }-\mathrm{S}_{\min }\right)}{\left(\mathrm{E}_{\max }-\mathrm{E}_{\min }\right)}+\mathrm{S}_{\min }
$$

$$
\begin{array}{cl}
\text { em que: } & \\
\mathrm{Y} & \text { - valor normalizado } \\
\mathrm{X} & \text { - valor de entrada } \\
\mathrm{E}_{\min } & \text { - menor valor de entrada } \\
\mathrm{E}_{\max } & \text { - maior valor de entrada } \\
\mathrm{S}_{\min } & \text { - menor valor de saída } \\
\mathrm{S}_{\max } & \text { - maior valor de saída }
\end{array}
$$

A obtenção dos indicadores se deu por meio da álgebra de cinco mapas primários referentes aos fragmentos florestais, áreas edificadas, malha viária, capacidade de uso das terras e uso e ocupação do solo na região de borda dos fragmentos florestais para cada respectiva data (1972, 2001 e 2013).

Os mapas primários foram obtidos através da interpretação visual das imagens digitais e delimitação vetorial no programa ArcGis (ESRI, 1999).

As tendências dos indicadores de perturbação ambiental foram caracterizadas por meio da análise de regressão linear e interpretadas com base nos coeficientes angulares das regressões.

Os pesos da análise multicritério foram determinados por Freitas (2012), buscando incorporar a percepção técnica de profissionais ligados às áreas geoprocessamento, conservação do solo e recursos naturais sobre a importância de cada indicador na qualidade ambiental de remanescentes florestais. A avaliação foi realizada com base em questionários com a adoção de uma escala numérica em sua ponderação.

Os valores de qualidade ambiental obtidos para 1972, 2001 e 2013 foram normalizados com adoção do mesmo método utilizado nos indicadores e estratificado em cinco classes de qualidade ambiental: muito baixa, baixa, moderada, alta e muito alta. Os resultados foram avaliados por meio da análise de frequência e análise gráfica das transições entre as classes.

\section{Resultados e Discuss ão}

$\mathrm{O}$ indicador de proximidade entre fragmentos florestais e áreas edificadas revelou a ocorrência de duas tendências na série histórica (Tabela 1). Em 1972 identifica-se um coeficiente angular $(\alpha)$ positivo na análise de regressão. O resultado mostra que há uma tendência linear e crescente de acúmulo de valores entre o intervalo 0 e 1 indicando, portanto, um acúmulo maior de valores próximos a 1 e menor perturbação ambiental pelo distanciamento entre as áreas edificadas e os remanescentes florestais.

Em 2001 e 2013 a tendência se inverte apresentando coeficientes angulares negativos. Nesses períodos ocorre um acúmulo maior de valores próximos a 0 e, consequentemente, maior proximidade entre as áreas florestais e as áreas edificadas. 
Tabela 1. Análise de regressão do indicador de perturbação ambiental de proximidade entre fragmentos florestais e áreas edificadas

\begin{tabular}{cccc}
\hline Distância entre & \multicolumn{3}{c}{ Análise de regressão } \\
\cline { 2 - 4 } $\begin{array}{c}\text { fragmentos florestais } \\
\text { e malha viária }\end{array}$ & $\begin{array}{c}\text { Coeficiente } \\
\text { angular }\end{array}$ & $\begin{array}{c}\text { Intervalo de } \\
\text { confiança (95\%) }\end{array}$ & valor-P \\
1972 & 0,28 & 0,25 a 0,32 & $2,40 \mathrm{E}-28^{*}$ \\
2001 & $-0,25$ & $-0,34$ a $-0,16$ & $1,32 \mathrm{E}-07^{*}$ \\
2013 & $-0,18$ & $-0,24$ a $-0,11$ & $5,84 \mathrm{E}-07^{*}$ \\
\hline
\end{tabular}

*Significativo a 0,05 de probabilidade

O indicador refletiu o processo de expansão urbana de $529,2 \%$ entre 1972 e 2013. As diferenças entre os coeficientes angulares são explicadas pelas taxas anuais de expansão urbana

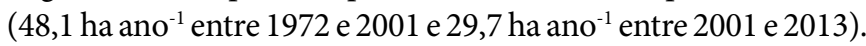

$\mathrm{O}$ indicador de proximidade entre fragmentos florestais e malha viária, embora apresente coeficientes angulares negativos (Tabela 2), indica aumento de concentração de valores próximos a 0 . Os resultados obtidos corroboram com a expansão de $232,3 \%$ da malha viária mostrando a aproximação entre as áreas de remanescentes e a malha viária.

Os resultados obtidos por Levinson \& Chen (2005) corroboram com os dos indicadores. A associação observada entre a expansão das áreas edificadas e a malha viária foi provada pelo autor em termos probabilismos nos municípios de Minneapolis e St. Paul nos EUA. As áreas agrícolas e florestais tenderam, com a presença de vias próximas, a apresentar maior probabilidade de conversão em áreas de moradia e industriais, uma vez que o processo de construção civil é facilitado com a expansão das vias de acesso.

Outro aspecto ligado aos indicadores de áreas impermeabilizadas é a ameaça aos recursos hídricos da bacia hidrográfica. Cerca de $20 \%$ das áreas remanescentes se localizam nas margens dos corpos d'água, em Áreas de Proteção Permanente (APP). A aproximação de áreas impermeabilizadas nesses locais pode contribuir para alterações significativas na hidrologia da bacia hidrográfica.

Poelmans et al. (2010) em um estudo realizado na bacia hidrográfica de Flanders-Brussels localizada na costa Oeste da Europa, identificaram, através de um processo de modelagem espacial, que as tendências do processo de ocupação da região com expansão de áreas impermeabilizadas variando entre 22 e $35 \%$, podem promover um aumento de $20 \%$ no escoamento superficial anual, 1,5\% de redução na evapotranspiração e $3 \%$ de diminuição do volume do lençol freático. No cenário pessimista os autores chegaram a $77 \%$ de aumento no escoamento superficial, 4,5\% de redução na evapotranspiração e $12 \%$ de diminuição do nível do lençol freático.

$\mathrm{O}$ indicador de suporte ao desenvolvimento da vegetação nativa mostrou ligeiras modificações nas características

Tabela 2. Análise de regressão do indicador de perturbação ambiental de proximidade entre fragmentos florestais e malha viária

\begin{tabular}{cccc}
\hline \multirow{2}{*}{$\begin{array}{c}\text { Distância entre fragmentos } \\
\text { florestais e malha viária }\end{array}$} & \multicolumn{3}{c}{ Análise de regressão } \\
\cline { 2 - 4 } & $\begin{array}{c}\text { Coeficiente } \\
\text { angular }\end{array}$ & $\begin{array}{c}\text { Intervalo } \\
\text { de confiança }\end{array}$ & valor-P \\
\hline 1972 & $-0,09$ & $-0,17$ a $-0,01$ & $0,02^{*}$ \\
2001 & $-0,55$ & $-0,67$ a $-0,43$ & $4,05 \mathrm{E}-15^{*}$ \\
2013 & $-1,56$ & $-1,7$ a $-1,37$ & $3,45 \mathrm{E}-30^{*}$ \\
\hline
\end{tabular}

${ }^{*}$ Significativo a 0,05 de probabilidade dos locais ocupados pelas áreas florestais (Tabela 3 ). Os resultados mostraram coerência com os obtidos por Freitas et al. (2013) na avaliação do mesmo indicador nas áreas de preservação permanente da Bacia Hidrográfica. Historicamente, os fragmentos florestais ocupam regiões de baixa aptidão do solo (Classes VI, VII e VIII), de menor capacidade produtiva e, consequentemente, de maior vulnerabilidade ambiental.

Além da maior dificuldade de recuperação desses locais, a regionalização das áreas florestais em locais que apresentam condições agronômicas restritivas pode contribuir para a diminuição da biodiversidade vegetal. Carvalho et al. (2008) observaram que embora sejam complexas as relações entre a comunidade vegetal e o ambiente, condições limitantes do solo resultam em alterações na diversidade e riqueza das espécies, sobretudo nos estratos de arbóreos mais desenvolvidos.

$\mathrm{O}$ indicador que relaciona o uso e a ocupação do solo e o efeito de borda, revelou coeficientes angulares negativos com ligeira diferença entre os valores de 1972 e 2001/2013 (Tabela 4).

Os resultados podem ser explicados pelas diferenças nos intervalos temporais das observações. Entre 1972 e 2001 a taxa de urbanização ocorreu próxima a 6,5\% ao ano, com a ocupação de classes ligadas à agricultura e pecuária $(83,9 \%$ da área total). Entre 2001 e 2013 a taxa de urbanização se mantém próxima ( $5 \%$ ao ano), com uma diminuição de $21,3 \%$ nas áreas rurais. Como o lapso temporal entre 1972 e 2001 é de 29 anos, o coeficiente angular apresentou uma redução maior nesse período.

Em 14 das 18 sub-bacias hidrográficas ocorreu diminuição na quantidade dos fragmentos florestais entre 1972 e 2001 (Tabela 5). O evento não indica o aumento na conectividade ou na dimensão das áreas florestais, sendo associado ao processo de desmatamento, com o desaparecimento de fragmentos florestais de menor dimensão.

Tabela 3. Classes de capacidade de uso das terras ocupadas pelos fragmentos florestais

\begin{tabular}{|c|c|c|c|c|c|}
\hline \multirow{2}{*}{$\begin{array}{l}\text { Classes de suporte } \\
\text { ao desenvolvimento } \\
\text { da vegetaçãa }\end{array}$} & \multirow{2}{*}{\multicolumn{2}{|c|}{$\begin{array}{l}\text { Classes de capacidade } \\
\text { de uso do solo* }\end{array}$}} & \multicolumn{3}{|c|}{ Área florestal (\%) } \\
\hline & & & 1972 & 2001 & 2013 \\
\hline $0,0-0,2$ & VIII & Vllefp & 70,1 & 72,3 & 73,9 \\
\hline $0,2-0,4$ & Vlef & Vlefp & 14,5 & 11,6 & 11,4 \\
\hline $0,4-0,6$ & Vle & $\mathrm{Va}$ & 6,2 & 6,8 & 8,9 \\
\hline $0,6-0,8$ & IVef & IVefp & 8,8 & 9,0 & 5,4 \\
\hline $0,8-1,0$ & Illef Illefp & IIIf IIf & 0,3 & 0,4 & 0,4 \\
\hline
\end{tabular}

*As classes de capacidade de uso representadas por números romanos (I, II, III, IV, V, VI, VII e VIII) denotam a limitação agrícola da terra, em que I está associado a nenhum grau de limitação e VIII denota altos graus de restrições. Letra minúscula a: representa a limitação do solo por toxicidade por alumínio; Letra minúscula e: áreas com suscetibilidade ao processo erosivo; Letra minúscula f: solos com deficiência de fósforo disponível; Letra minúscula $p$ : restrições ligadas a profundidade efetiva do solo

Tabela 4. Análise de regressão do indicador de perturbação ambiental de uso e ocupação do solo na borda dos fragmentos florestais

\begin{tabular}{|c|c|c|c|}
\hline \multirow{2}{*}{$\begin{array}{c}\text { Uso e ocupação } \\
\text { do solo na borda } \\
\text { dos fragmentos florestais }\end{array}$} & \multicolumn{3}{|c|}{ Análise de regressão } \\
\hline & $\begin{array}{l}\text { Coeficiente } \\
\text { angular }\end{array}$ & $\begin{array}{c}\text { Intervalo } \\
\text { de confiança }\end{array}$ & valor-P \\
\hline 1972 & $-1,19$ & $-1,54$ a $-0,83$ & $2,708 \mathrm{E}-09$ \\
\hline 2001 & $-1,62$ & $-2,01$ a $-1,24$ & $1,552 \mathrm{E}-12^{*}$ \\
\hline 2013 & $-1,62$ & $-2,01 \mathrm{a}-1,22$ & $3,29 \mathrm{E}-12$ \\
\hline
\end{tabular}

${ }^{*}$ Significativo a 0,05 de probabilidade 
Tabela 5. Evolução da fragmentação florestal e cobertura vegetal natural nas sub-bacias hidrográficas

\begin{tabular}{|c|c|c|c|c|c|c|c|c|c|}
\hline \multirow{2}{*}{ Sub-bacias hidrográficas } & \multicolumn{3}{|c|}{$\mathrm{N}^{\circ}$ de fragmentos florestais } & \multicolumn{3}{|c|}{ Intensidade da fragmentação florestal } & \multicolumn{3}{|c|}{ Área florestal (\%) } \\
\hline & 1972 & 2001 & 2013 & 1972 & 2001 & 2013 & 1972 & 2001 & 2013 \\
\hline Caxambu & 46 & 32 & 41 & 0,46 & 0,32 & 0,41 & 15 & 13 & 17 \\
\hline Córrego Albino & 12 & 16 & 44 & 0,27 & 0,36 & 1 & 29 & 24 & 22 \\
\hline Córrego Ananas & 27 & 12 & 15 & 0,78 & 0,34 & 0,43 & 13 & 11 & 13 \\
\hline Córrego Caxambuzinho & 20 & 14 & 15 & 0,57 & 0,4 & 0,43 & 42 & 31 & 33 \\
\hline Córrego da Roseira & 38 & 37 & 52 & 0,26 & 0,25 & 0,35 & 22 & 29 & 35 \\
\hline Córrego do Areião & 65 & 32 & 37 & 0,77 & 0,38 & 0,44 & 20 & 18 & 20 \\
\hline Córrego do Perdão & 83 & 36 & 73 & 0,39 & 0,17 & 0,35 & 24 & 21 & 24 \\
\hline Córrego Ponte Alta & 62 & 45 & 68 & 0,4 & 0,29 & 0,44 & 18 & 14 & 18 \\
\hline Escada Dissipação & 38 & 31 & 50 & 0,24 & 0,2 & 0,32 & 21 & 20 & 20 \\
\hline Horto & 10 & 7 & 6 & 0,21 & 0,14 & 0,12 & 10 & 6 & 6 \\
\hline Calha do Rio Jundiaí-Mirim & 52 & 32 & 60 & 0,36 & 0,22 & 0,42 & 27 & 30 & 32 \\
\hline Parque Centenário & 19 & 10 & 13 & 0,47 & 0,25 & 0,32 & 16 & 13 & 15 \\
\hline Pinheirinho & 33 & 26 & 25 & 0,47 & 0,37 & 0,35 & 15 & 16 & 16 \\
\hline Represa Nova & 18 & 14 & 12 & 0,73 & 0,57 & 0,49 & 24 & 26 & 25 \\
\hline Ribeirão da Toca & 25 & 20 & 28 & 0,43 & 0,34 & 0,48 & 25 & 26 & 31 \\
\hline Ribeirão do Tanque & 26 & 39 & 64 & 0,14 & 0,21 & 0,34 & 38 & 35 & 35 \\
\hline Ribeirão dos Soares & 28 & 12 & 36 & 0,16 & 0,07 & 0,21 & 53 & 46 & 44 \\
\hline Taruma & 13 & 10 & 4 & 0,23 & 0,18 & 0,07 & 4 & 6 & 6 \\
\hline
\end{tabular}

O indicador de fragmentação florestal das sub-bacias hidrográficas exige a interpretação de seus resultados integrada a outras informações visto que a presença de apenas um fragmento florestal altamente perturbado classificaria a subbacia hidrográfica como próxima da condição ideal.

Os fragmentos florestais de 1,0 a 5,0 ha apresentam-se predominantes em número e os superiores a 20,0 ha em área ocupada (Figura 1A). Entre 1972 e 2001 identificou-se a diminuição dos fragmentos florestais com área inferior a 0,5 ha e o aumento dos de dimensão entre 1,0 e 5,0 ha. A partir de 2001 observou-se o aumento dos fragmentos florestais com dimensão superior a 5,0 ha e a diminuição de tamanho inferior a 5,0 ha. Observa-se que a maior parte dos fragmentos florestais apresenta circularidade entre 0,6 e 0,8 (Figura 1B). Os resultados revelam que os fragmentos florestais passaram a assumir formas alongadas e menores dimensões.

$\mathrm{Na}$ série histórica poucos fragmentos florestais se apresentaram isolados a uma distância superior a $350 \mathrm{~m}$ (Tabela 6). Observa-se que o valor de fragmentos não conectados é maior em 2001 e em 2013 atingiu um valor próximo do existente em 1972.

Os resultados da integração dos indicadores de perturbação ambiental através da análise multicriterial, mostram o provável grau de alteração das áreas florestais frente ao processo de ocupação da bacia hidrográfica (Figura 2)

As áreas com qualidade ambiental muito alta representam aquelas pouco alteradas, com características próximas da vegetação natural original; sua presença é identificada em regiões distantes das fontes de perturbação ambiental, em locais afastados das áreas urbanizadas e com menor intensidade de uso do solo; as de alta qualidade mostram regiões que apresentam algum grau de alteração, porém as características da vegetação natural original são conservadas; são identificadas em locais que apresentam algum processo de urbanização, proximidade com as vias de acesso ou a presença de atividades de uso do solo com maior potencial de perturbação; as classificadas com qualidade moderada representam áreas que apresentam moderado grau de alteração da vegetação natural e cuja vegetação resultante apresenta características diferentes das originais devido à maior influência de áreas

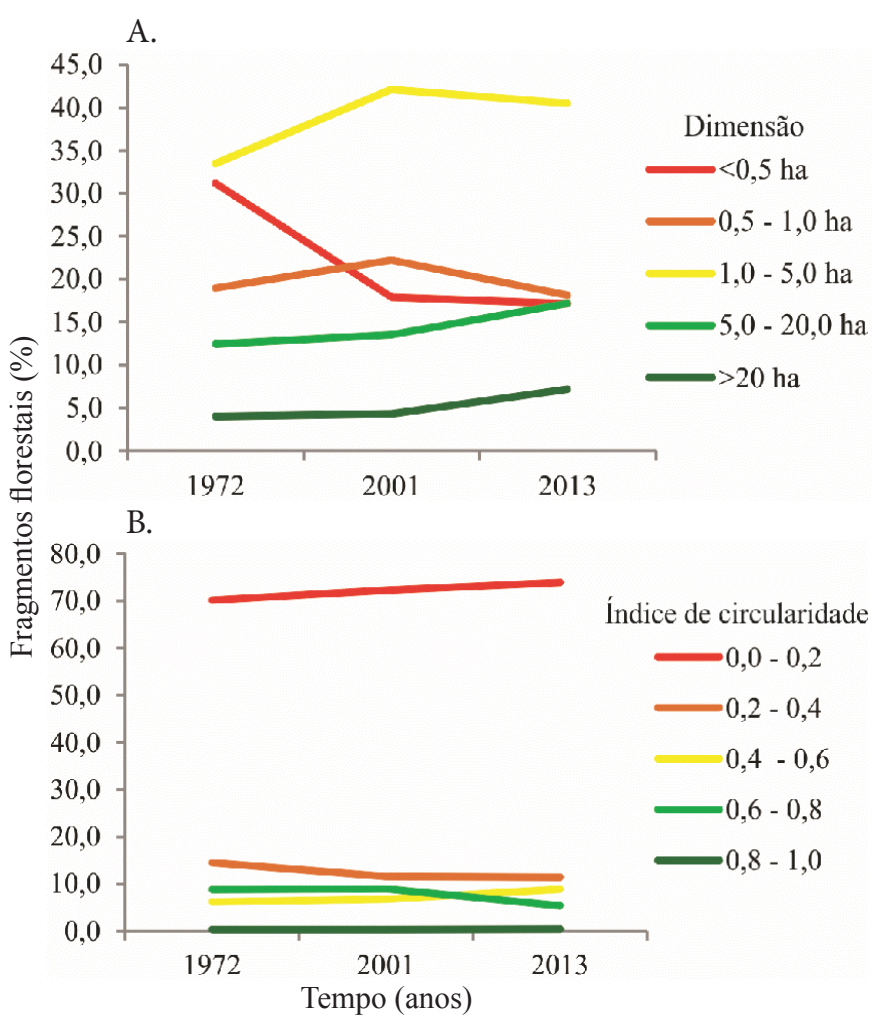

Figura 1. Modificações na dimensão (A) e na forma dos fragmentos florestais (B) entre 1972 e 2013

Tabela 6. Evolução da conectividade dos fragmentos florestais (CFF) entre 1972 e 2013

\begin{tabular}{|c|c|c|c|c|c|c|}
\hline & \multicolumn{6}{|c|}{ Fragmentos florestais } \\
\hline & \multicolumn{2}{|c|}{1972} & \multicolumn{2}{|c|}{2001} & \multicolumn{2}{|c|}{2013} \\
\hline & $\%$ & Quant. & $\%$ & Quant. & $\%$ & Quant. \\
\hline Desco & 0,4 & 2,0 & 1,5 & 6,0 & 0,5 & 3,0 \\
\hline Conectados & 99,6 & 529,0 & 98,5 & 401,0 & 99,5 & 416,0 \\
\hline
\end{tabular}

CFF - Conectividade dos fragmentos florestais; Quant. - Quantidade

edificadas, malha viária e atividades de uso do solo. Os locais de baixa qualidade constituem áreas em contato direto com fontes perturbadoras, com significativo grau de alteração da vegetação natural.

Os classificados com qualidade muito baixa representam áreas altamente perturbadas que, além do contato direto 


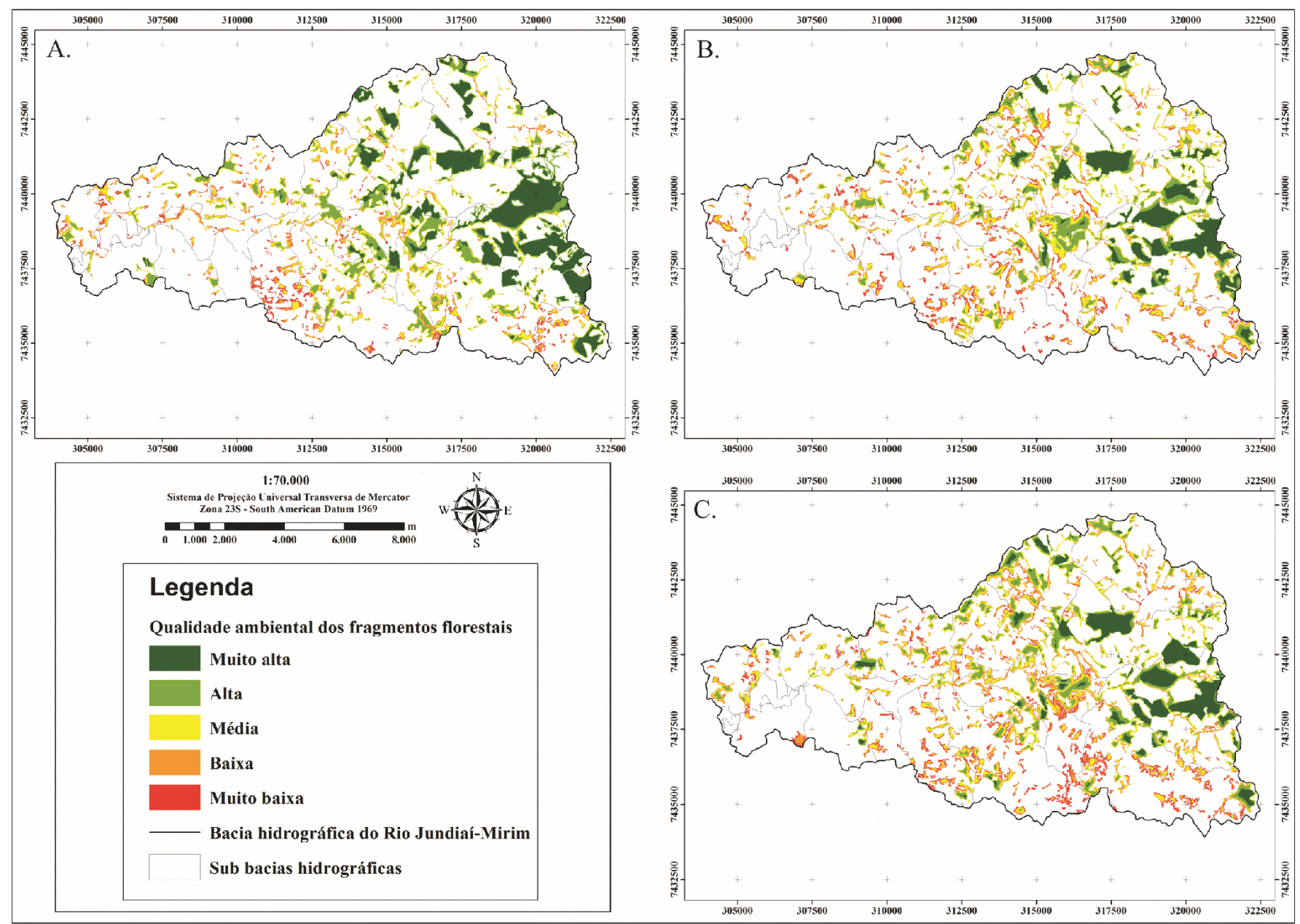

Figura 2. Qualidade ambiental dos fragmentos florestais da bacia hidrográfica do Rio Jundiaí-Mirim: 1972 (A), 2001 (B) e 2013 (C)

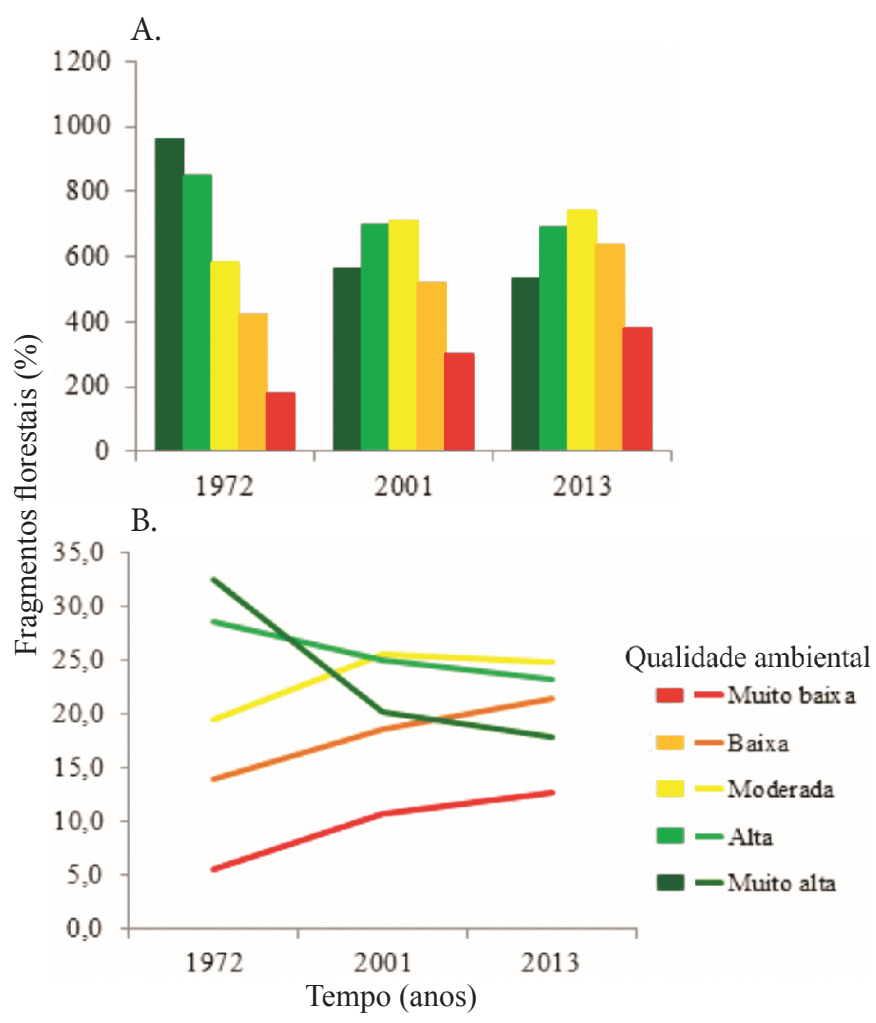

Figura 3. Evolução da qualidade ambiental dos fragmentos florestais da bacia hidrográfica do Rio Jundiaí-Mirim: histograma de classes (A) e transição de classes (B) com áreas urbanizadas ou atividades de uso intenso do solo, apresentam elevada vulnerabilidade ao processo de ocupação.

Em 1972 ocorre predomínio das classes muito alta e alta, correspondendo a 1786 ha ou $61 \%$ da área total dos fragmentos florestais (Figura 3A). Entre 2001 e 2013 as distribuições se aproximam de uma forma Gaussianas e as classes alta e muito alta apresentam redução de 26 e 32\% em relação a 1972; as áreas ocupadas pelas classes de qualidade ambiental baixa e muito baixa apresentaram aumento crescente (Figura 3B). É notável a diminuição da classe muito alta, sobretudo no período entre 1972 e 2001.

Os resultados são explicados pelo aumento da perturbação ambiental nos fragmentos florestais em decorrência do intenso processo de urbanização da bacia hidrográfica. O desmatamento, a fragmentação florestal e a urbanização da bacia hidrográfica contribuíram significativamente para a deterioração da qualidade ambiental dos remanescentes florestais no período de análise sendo, a partir de 2001, constituído um novo cenário devido o processo intenso de ocupação do local.

\section{Conclusões}

1. O processo de urbanização, aliado ao desmatamento e à fragmentação florestal, promoveram deterioração significativa da qualidade ambiental dos fragmentos florestais entre 1972 e 2013. 
2. A metodologia empregada possibilitou entender o processo evolutivo da qualidade ambiental dos fragmentos florestais na bacia hidrográfica do Rio Jundiaí-Mirim frente ao intenso processo de urbanização da região.

3. Considerando a importância da bacia hidrográfica, os resultados demonstram a premente necessidade de criação de políticas públicas específicas para a preservação da vegetação natural do manancial e de diretrizes para sua gestão.

\section{Literatura Citada}

Alkharabsheh, M. M.; Alexandridis, T. K.; Bilas, G.; Misopolinos, N.; Silleo, N. Impact of land cover change on soil erosion hazard in Northern Jordan using remote sensing and GIS. Procedia Environmental Sciences, v.19, p.912-921, 2013. http://dx.doi. org/10.1016/j.proenv.2013.06.101

Bracchetti, L.; Carotenuto, L.; Catorci, A. Land-cover changes in a remote area of central Apennines (Italy) and management directions. Landscape and Urban Planning, v.104, p.157-170, 2012. http://dx.doi.org/10.1016/j.landurbplan.2011.09.005

Carvalho, J.; Marques, M. C. M.; Roderjan, C. V.; Barddal, M.; Sousa, S. G. A. de. Relações entre a distribuição das espécies de diferentes estratos e as características do solo de uma floresta aluvial no Estado do Paraná, Brasil. Acta Botanica Brasilica, v.23, p.1-9, 2009. http://dx.doi.org/10.1590/S0102-33062009000100002

Chaves, H. M. L.; Santos, L. B. dos. Ocupação do solo, fragmentação da paisagem e qualidade da água em uma pequena bacia hidrográfica. Revista Brasileira Engenharia Agrícola e Ambiental, v.13, p.922-930, 2009. http://dx.doi.org/10.1590/ S1415-43662009000700015

ENVI - Environment for Visualizing Images. Curso avançado (Manual do Curso de Envi 4.6) Sulsoft, 2009.

ESRI - Environmental Systems Research Institute. Getting to know ArcView GIS. Redlands: Esri Press, 1999.

Freitas, E. P. Análise integrada do mapa de uso e ocupação das terras da microbacia do Rio Jundiaí-Mirim para fins de gestão ambiental. Campinas: Instituto Agronômico de Campinas, 2012. 110p. Dissertação Mestrado

Freitas, E. P.; Moraes, J. F. L. de.; Peche Filho, A.; Storino, M. Indicadores ambientais para áreas de preservação permanente. Revista Brasileira Engenharia Agrícola e Ambiental, v.17, p.443449, 2013. http://dx.doi.org/10.1590/S1415-43662013000400013

Haines-Young, R. Land use and biodiversity. Land Use Policy, v.26, p 178-186, 2009. http://dx.doi.org/10.1016/j. landusepol.2009.08.009

ITC - International Institute for Aeroespace Survey and Earth Sciences. Ilwis; User's Guide. Holanda: Enschede, 2001. 530p.
Levinson, D.; Chen, W. Paving new ground: A Markov Chain model of the change in transportation networks and land use. In: Levinson, D.; Krizek, K. J. (Ed.). Access to Destinations. 1.ed. Minessota: Elsevier Science, 2005. p.243-266.

Li, Z.; Liu, W.; Zhang, X.; Zheng, F. Impacts of land use change and climate variability on hydrology in an agricultural catchment on the Loess Plateau of China. Journal of Hydrology, v.377, p.35-42, 2009. http://dx.doi.org/10.1016/j.jhydrol.2009.08.007

Mondal, P.; Southworth, J. Evaluation of conservation interventions using a cellular automata-Markov model. Forest Ecology and Management, v.260, p.1716-1725, 2010. http://dx.doi. org/10.1016/j.foreco.2010.08.017

Moraes, J. F. L.; Carvalho, Y. M. C.; Peche Filho, A. Diagnóstico agroambiental para a gestão e monitoramento da Bacia do Rio Jundiaí-Mirim. In: Hamada, E. (ed.), Água, agricultura e meio ambiente no Estado de São Paulo: Avanços e desafios. Jaguariúna: Embrapa Meio Ambiente, cap. III, 2003, CD-Rom

Newman, M. E.; Maclaren, K. P.; Wilson, B. S. Assessing deforestation and fragmentation in a tropical moist forest over 68 years; the impact of roads and legal protection in the Cockpit Country, Jamaica. Forest Ecology and Management, v.315, p.138-152, 2014. http://dx.doi.org/10.1016/j.foreco.2013.12.033

Ozturk, M. Copty, N. K.; Saysel, A. K. Modeling the impact of land use change on the hydrology of a rural watershed. Journal of Hydrology, v.497, p.97-109, 2013. http://dx.doi.org/10.1016/j. jhydrol.2013.05.022

Poelmans, L.; Rompaey, A. V.; Batelaan, O. Coupling urban expansion models and hydrological models: How important are spatial patterns?. Land Use Policy, v.27, p.965-975, 2010. http://dx.doi. org/10.1016/j.landusepol.2009.12.010

Prado, T. B. G. Evolução do uso das terras e produção de sedimentos na bacia hidrográfica do Rio Jundiaí-Mirim. Campinas: Instituto Agronômico de Campinas, 2005. 72p. Dissertação Mestrado

Ramos, C.; Simonetti, J. A.; Flores, J. D.; Ramos-Jiliberto, R. Modelling the management of fragmented forests: Is it possible to recover the original tree composition? The case of the Maulino forest in Central Chile. Forest Ecology and Management, v 255, p.22362243, 2008. http://dx.doi.org/10.1016/j.foreco.2007.12.034

Ruhoff, A. L.; Fantin-Cruz, I.; Collischonn, W. Modelos de simulação dinâmica do desmatamento na Amazônia. Caminhos de Geografia, v.11, p.258-268, 2010.

Vieira, M. V.; Olifiers, N.; Delciellos, A. C.; Antunes, Vanina Z.; Bernardo, L. R.; Carlos E.V. Grelle, R. C.; Land use vs. fragment size and isolation as determinants of small mammal composition and richness in Atlantic Forest remnants. Biological Conservation, v.142, p.1191-1200, 2009. http://dx.doi. org/10.1016/j.biocon.2009.02.006 